\title{
Comparative Immunomodulatory Activity of Ascaris Suum Eggs and Dermatophagoides pteronyssinus Extract in BALB/c Mice: Cytokine and Immunoglobulin Regulations
}

Pineda, Maria Ruth $B^{1,2,4 *}$ and Ramos, John Donnie $A^{1,3,4}$

${ }^{1}$ UST Graduate School, University of Santo Tomas, Manila, Philippines

${ }^{2}$ Faculty of Pharmacy, University of Santo Tomas, Manila, Philippines

${ }^{3}$ College of Science, University of Santo Tomas, Manila, Philippines

${ }^{4}$ Research Cluster for the Natural and Applied Sciences, University of Santo Tomas, Philippines

\begin{abstract}
Allergy is highly prevalent in well-developed countries; hygiene hypothesis suggests that this is due to exposure to previous bacterial infection eliciting Th1-response that suppresses Th2-mediated responses. Aside from Th2 suppressing Th1-responses, Th2-mediated infections such as parasitism, appear to lower the risk of developing allergy. This study investigates the effects of Ascaris suum infection in Dermatophagoides pteronyssinus-induced allergic BALB/c mice. Ninety BALB/c mice divided into three trials were randomly grouped into: normal control (1), A. suum infected mice (2), D. pteronyssinus exposed mice (3), A. suum infected mice and then exposed to $D$. pteronyssinus (4), D. pteronyssinus exposed mice and then infected with $A$. suum (5), and mice exposed and infected with $D$. pteronyssinus and $A$. suum, simultaneously (6). Blood and fecal samples were collected at days 0 , 36, and 72 for the measurement of cytokines and immunoglobulins through ELISA, and for fecal analysis. Results showed that $A$. suum infection suppressed $D$. pteronyssinus-induced allergy morphologically and histologically and downregulated the production of $D$. pteronyssinus-specific IgE. A. suum and $D$. pteronyssinus upregulated the production of IL-4 and IL-5, and only $A$. suum eggs enhanced the production of IL-10. D. pteronyssinus enhanced production of both $D$. pteronyssinus-specific and $A$. suum-specific $\lg E$ and $\lg G$ and may be accounted to crossreacting antigens present in $D$. pteronyssinus and $A$. suum. IL-10 is upregulated in mice with $A$. suum infection and appears to protect mice against $D$. pteronyssinus-induced allergy. The possible role of IL-10 production in response to $A$. suum infection and against $D$. pteronyssinus-induced allergy needs further investigation.
\end{abstract}

Keywords: Hygiene; Ascaris suum; Dermatophagoides pteronyssinus; Allergy; Infection; Cytokines; Immunoglobulins

Abbreviations: A. suum: Ascaris suum; D. pteronyssinus: Dermatophagoides pteronyssinus

\section{Introduction}

Hygiene hypothesis is a proposed theoretical framework explaining the protection developed by an individual against certain diseases such as allergies as a result of previous exposure to infectious agents especially during childhood [1]. This hypothesis suggests that increase in the prevalence of chronic inflammatory disorders, such as allergies and autoimmunity in developed countries is attributable to diminishing exposure to the usual organisms in the environment, which have long been a part of the mammalian evolutionary history $[2,3]$.

Most investigations on hygiene hypothesis focus on infections eliciting Th1 responses, like bacterial infections, to counteract certain immune reactions associated with Th2 response such as allergic reactions. Although a significant number of infectious agents that develop Th1 response have been thoroughly studied, the role of parasitic infections in allergies remains unresolved. Allergy and parasitism both induce Th2 immune response $[4,5]$. The shift from Th1 to Th2 or vice versa associated with the hygiene hypothesis is controversial because of contradicting results by a number of studies. On the one hand, some studies show that decrease in parasitic cases is associated with increasing cases of allergic diseases $[6,8]$. On the other hand, in a study conducted among preschool-aged Brazilian children, it showed that Ascaris lumbricoides and Trichuris trichiura infections are risk factors in the development of atopy. Thus children with parasitic infections are more prone to atopy and experience wheezing [9]. Still, another study conducted in Rural China showed children with A. lumbricoides infection have increased risk of developing asthma. This manifestation is associated with sensitization to some aeroallergens [10].

The conflicting results on the role of helminth infections in the development of allergic diseases necessitate further studies. Helminth infections and allergy highly induce Th2 immune response [4,5]. Both allergy and helminth infections are associated with elevated levels of immunoglobulin E (IgE), tissue eosinophilia, mastocytosis, and Th2 cytokines IL-4 and IL-5. Because of these similarities in immune response, as well as the issue on hygiene hypothesis, it has been debated that Th2-response in helminth infection can protect an individual from allergic condition. IL-10 was also measured, since some studies have mentioned the inhibitory effect of this interleukin against other interleukins such as IL-4 and IL-5, thus, conferring resistance or protection for the host from developing lethal immunopathology [11]. IL-10 is usually induced in cases of chronic helminthiasis, together with TGF- $\beta$ and IgG instead of IgE $[3,12]$. This present study examines

*Corresponding author: Pineda, Maria Ruth B. 2nd Floor Main Building Department of Medical Technology, Faculty of Pharmacy, University of Santo Tomas, Manila, Philippines, Tel: (02)-406-1611 local 8398; Fax: (+63)-9064971267; E-mail: mariaruthpineda@gmail.com

Received July 19, 2012; Accepted August 27, 2012; Published August 30, 2012

Citation: Pineda MRB, Ramos JDA (2012) Comparative Immunomodulatory Activity of Ascaris Suum Eggs and Dermatophagoides pteronyssinus Extract in BALB/c Mice: Cytokine and Immunoglobulin Regulations. J Aller Ther 3:119. doi:10.4172/2155-6121.1000119

Copyright: @ 2012 Pineda MRB, et al. This is an open-access article distributed under the terms of the Creative Commons Attribution License, which permits unrestricted use, distribution, and reproduction in any medium, provided the original author and source are credited. 
Citation: Pineda MRB, Ramos JDA (2012) Comparative Immunomodulatory Activity of Ascaris Suum Eggs and Dermatophagoides pteronyssinus Extract in BALB/C Mice: Cytokine and Immunoglobulin Regulations. J Aller Ther 3:119. doi:10.4172/2155-6121.1000119

the role of A. suum infection in D. pteronyssinus-induced allergy in $\mathrm{BALB} / \mathrm{c}$ mice. Potential application of Hygiene hypothesis is indirectly investigated in this study by comparing the levels of interleukins and immunoglobulins involved in the immunology of helminth infection and allergy. Can A. suum infection protect $\mathrm{BALB} / \mathrm{c}$ mice against $D$. pteronyssinus-induced allergy?

\section{Materials and Methods}

\section{Study design}

BALB/c mice $(n=90), 6$ to 8 weeks old, obtained from the University of the Philippines National Institute of Health, were used in this study. Permit to handle and use animals in research was secured from the University of Santo Tomas Institute of Animal Care and Use Committee (IACUC), with Permit No. AR-2011-2015. The mice were housed in the Thomas Aquinas Research Complex Animal House. They were acclimatized for two weeks, prior to the start of experimentation. Mice were treated and handled humanely following standard IACUC guidelines. Ninety BALB/c mice divided into three trials were randomly assigned into six groups labeled as normal control (1), A. suum infected mice (2), D. pteronyssinus-allergic mice (3), A. suum infected mice then exposed to $D$. pteronyssinus (4), D. pteronyssinus-allergic mice then infected with A. suum (5), and simultaneously infected with $A$. suum and exposed to D. pteronyssinus (6).

$\mathrm{BALB} / \mathrm{c}$ mice in groups 2, 4, 5, and 6 received approximately

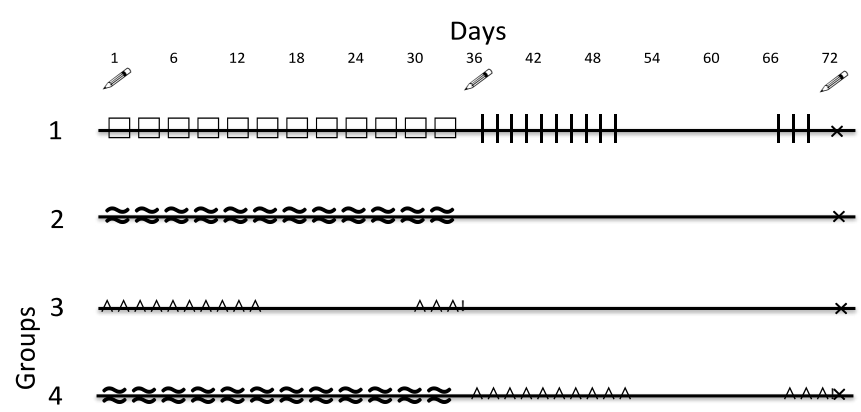

5

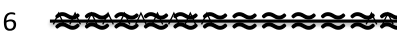

Legend:
$\square$ oral gavage of distilled water

$\approx$ oral gavage of A.\#tuum拉gs

Blood Collection

I intranasal administration of NSS

$\wedge$ intranasal administration of $D$. \#teronyssinusłallergen

$x$ end of experiment

Figure 1: Infection/Induction Protocol. BALB/c mice were grouped into six groups.

Group 1 received only distilled water from days 1 to 36 and NSS from days 37 to 72 as placebo.

Group 2 received $A$. suum eggs every three days from days 1-36.

Group 3 received $D$. pteronyssinus extract from days $1-10$ and booster from days 31-33.

Group 4 received $A$. suum eggs from days 1-36 every three days and $D$. pteronyssinus extract from days 37-46 and booster dose from days 66-69.

Group 5 received $D$. pteronyssinus extract from day 1-10 and from days 31-33 and received $A$. suum eggs every three days from days 37 to 72 .

Group 6 received $A$. suum eggs every three days from days 1-36 and $D$. pteronyssinus extract from days 1-10 and from days 31-33.

Blood extraction and fecalysis were done at days 1, 36 and 72 . At day 72 , three mice per group were sacrificed for histopathologic analysis of the lungs, liver and intestines.
25,000 A. suum infective eggs suspended in $250 \mathrm{uL}$ distilled water via oral gavage every three days. Groups 2, 4 and 6 received $A$. suum eggs starting from day 1 to day 36 while group 5 received $A$. suum eggs from day 37 to 72 . This concentration mimicked chronic parasitism [13,14] Via intranasal route, D. pteronyssinus extract was given to groups 3, 4, 5 , and 6 groups of $\mathrm{BALB} / \mathrm{c}$ mice at $2.5 \mathrm{mg} / \mathrm{mL}$ concentration suspended in $10 \mathrm{uL}$ normal saline solution (NSS) to induce allergy [15]. Extract was administered for ten consecutive days dropwise, alternating between either nostril. Three weeks after the last dose, booster dose of $D$. pteronyssinus extract was given for three consecutive days. This procedure was given to groups 2,5 , and 6 starting on day 1 to 10 , and booster dose from day 31 to 33 , and to group 4 starting on Day 37 to 46 and booster dose from day 66 to 69 (Figure 1). NC group received only placebo, i.e., oral gavage of distilled water from day 1 to 36 and intranasal administration of NSS from day 37 to 46 and 66 to 69 , respectively.

\section{D. pteronyssinus extract}

Ten grams of pure cultures of $D$. pteronyssinus were wrapped in aluminum foil and soaked in liquid nitrogen for twenty minutes. A total volume of $50 \mathrm{~mL}$ of $1 \mathrm{X}$ Tris-Buffered Saline (TBS) with $2 \mathrm{mM}$ Phenyl Methyl Sulfonyl Fluoride (PMSF) (Sigma-Aldrich, Saint Louis, MO, USA) and $1 \mathrm{mM}$ EDTA (BioRad, Hercules, CA, USA) were added slowly while grinding the mites for at least 30 minutes. After 16 hours of incubation at $4^{\circ} \mathrm{C}$ with constant shaking, the extract suspension was centrifuged at 10,000 rpm for 20 minutes (Hettich). Supernatant was collected and stored in $-20^{\circ} \mathrm{C}$ freezer (Sanyo ${ }^{\circledR}$ Biomedical Freezer) until used. Protein content of the extract was quantified using the BioRad Protein Assay [16,17].

\section{A. suum egg suspension}

Adult A. suum worms were obtained from a slaughter house in La Loma, Quezon City, Philippines. Only female worms were used in this study. Worms were dissected longitudinally [18]. Uterus of each worm was isolated and placed in a mortar and pestle. Distilled water was added dropwise and the uterus was macerated into a paste-like consistency. A. suum egg suspension was examined under a compound microscope (low and high power objective). The suspension was then placed inside a petri dish with a moistened filter paper and stored under light protection at room temperature $\left(25^{\circ} \mathrm{C}\right)$. The petri dishes were continuously moistened with distilled water to prevent dryness. Eggs were monitored everyday starting at day 8 until the infective stage of A. suum was observed (egg with larva inside). Culture of the infective egg stage was stored in an amber bottle with water until used. Culture is checked daily to ensure the eggs survival. Infective egg stage of $A$. suum will not hatch and will not undergo any developmental stage unless ingested by a host.

\section{Blood collection}

Blood samples were collected retro-orbitally from the mice at days 0,36 and 72. Pasteur pipette was inserted in the medial portion of the eye. Approximately $500 \mathrm{uL}$ of blood sample per mice was collected and placed in a yellow microtainer tube with gel separator and clot activator (Beckton Dickinson). The tube was then centrifuged at room temperature at 10,844 g for 5 minutes (Hettich). Sera collected were stored at $-20^{\circ} \mathrm{C}$ until used (Sanyo ${ }^{\circledR}$ Biomedical Freezer).

\section{Measurement of interleukins}

Levels of interleukins IL-4, IL-5 and IL-10 were measured from blood sera using sandwich Enzyme Linked-Immunosorbent Assay 
Citation: Pineda MRB, Ramos JDA (2012) Comparative Immunomodulatory Activity of Ascaris Suum Eggs and Dermatophagoides pteronyssinus Extract in BALB/C Mice: Cytokine and Immunoglobulin Regulations. J Aller Ther 3:119. doi:10.4172/2155-6121.1000119

(Biolegend, Inc., USA) following the procedures provided by the manufacturer with slight modifications. In brief, $50 \mathrm{uL}$ of diluted capture antibody (anti-mouse IL-4, anti-mouse IL-5, and anti-mouse IL-10) were incubated overnight at $4^{\circ} \mathrm{C}$ followed by one hour blocking step at room temperature with $100 \mathrm{uL} 1 \mathrm{X}$ assay diluents. Samples and standards were added to appropriate wells and incubated for two hours at room temperature. Plates were then incubated with 50 $\mathrm{uL}$ of detection antibody for 1 hour followed by addition of $50 \mathrm{uL}$ of diluted Avidin-Horse Radish Peroxidase (HRP) for 30 minutes at room temperature. Plates were washed with $200 \mathrm{uL}$ of wash buffer between incubation steps. Detection was performed by incubation with 50 uL tetramethyl benzidine (TMB) substrate solution for 20 minutes. Colorimetric reaction was stopped by adding $50 \mathrm{uL}$ of $2 \mathrm{~N}$ sulfuric acid as stop solution to each well. Immediately within 30 minutes, absorbance was read at 450 nanometer $(\mathrm{nm})$. The detection limits of the assays were 1 picogram/milliliter $(\mathrm{pg} / \mathrm{mL}), 4 \mathrm{pg} / \mathrm{mL}$, and $16 \mathrm{pg} / \mathrm{mL}$ for IL-4, IL-5, and IL-10, respectively.

\section{Measurement of antigen-specific immunoglobulins}

Serum levels of antigen specific IgE and IgG were measured through Indirect ELISA. Briefly, ELISA plate was coated with $50 \mathrm{uL}$ of either $5 \mathrm{ug} / \mathrm{mL} D$. pteronyssinus extract antigen or A. suum antigen in $0.1 \mathrm{M} \mathrm{NaHCO}_{3}$ at $\mathrm{pH} 8.4$ overnight. After washing, plate was blocked with $50 \mathrm{uL}$ 1\% BSA (bovine serum albumin) in PBS-T for two hours at RT. Sera was added at 1:10 dilution, followed by incubation with $50 \mathrm{uL}$ of biotin anti-mouse $\operatorname{IgE}$ (or IgG) and $50 \mathrm{uL}$ of ExtraAvidin Alkaline phosphatase. Reaction was developed in the dark at RT for 60 minutes by using $50 \mathrm{uL}$ p-nitrophenyl phosphate (PNPP). Absorbance was read at $405 \mathrm{~nm}$ using an ELISA reader [13,16,19-21].

\section{Histopathology}

At day 72, mice were sacrificed and lungs, liver, and small intestines were harvested. Specimens were fixed in $10 \%$ formalin, and processed using routine histopathology procedures. Processed specimens were embedded in paraffin, sectioned and stained with hematoxylin and eosin solution [18]. Slides were examined by a pathologist blinded to the exposure status of the individual mice under the microscope using low and high power objective, with $100 \mathrm{X}$ and $400 \mathrm{X}$ magnification (Olympus). Scoring system was used to assess the pathology of the different organs. Lung sections were scored according to the following criteria: a. eosinophil infiltration $0=$ absent, $1=$ low grade cell influx, $2=$ moderate cell infiltration, low grade tissue damage, $3=$ moderate cell influx, marked tissue damage, $4=$ high cell influx and significant tissue pathology; b. mucosal edema $0=$ normal, $1=$ low grade diffuse edema, $2=$ moderate edema with moderately increased mucus production, $3=$ pronounced edema wit excessive mucus production; and c. epithelial cell damage $0=$ normal, $1=$ low grade epithelial cell loss, $2=$ moderate grade epithelial cell loss, 3 =high grade cell loss, epithelial metaplasia [22]. Liver was scored using the following criteria: a. gross $0=$ normal, $1=$ slight change in color, no visible necrosis, $2=$ change in color with moderate lesions, $3=$ change in color with severe necrosis; b. cellular infiltrate $0=$ absent, $1=$ one focal infiltrate, $2=$ multifocal infiltrate $(<10$ per field), $3=$ diffuse infiltrate $(>10$ per field); and $c$. necrosis $0=$ no visible necrosis, $1=$ small areas of necrosis, $2=$ moderate levels of necrosis $(<50 \%), 3=$ marked necrosis $(>50 \%)$ [23]. Sections of intestines were scored using the following criteria: $0=$ normal villi, $1=$ villi with tip distortion, $2=$ presence of Guggenheim's spaces, $3=$ villi with patchy disruption of the epithelial cells, $4=$ villi with exposed but intact lamina propria with sloughing, $5=$ exuded lamina propria, $6=$ villi with hemorrhage or denuded villi [24].

\section{Statistical analyses}

Mean and its standard errors (SEM) were used to summarize the data gathered. Mixed Model Analysis of Variance was used to determine if there is a significant difference among the groups (1-6), and trials (trial 1, trial 2 and trial 3 ). The groups were considered as fixed factors and the trials as random factors. In addition, Repeated Measures Analysis of Variance (RMANOVA) was used to determine if there is a significant change in the means from the baseline, with Bonferroni correction was used to compare the baseline with the third extraction. All statistical tests were performed at $5 \%$ level of significance using SPSS 17.0 for Windows.

\section{Results}

\section{D. pteronyssinus extract and A. suum eggs upregulates IL-4 and IL-5 production}

IL-4 and IL-5 levels increased significantly in BALB/c mice exposed to $D$. pteronyssinus extract and in mice infected with $A$. suum eggs. $\mathrm{BALB} / \mathrm{c}$ mice in group 1 did not show any significant change in the level of IL-4 from day 0 to $36(\mathrm{p}=0.266)$ and from day 36 to 72 $(\mathrm{p}=0.092)$. Enhanced production of IL-4 was observed in groups 2, 3, 4,5 , and 6 (Figure $2 \mathrm{~A}$ ). In group 2, although A. suum eggs did not immediately increase the level of IL-4 at day $36(\mathrm{p}=0.071)$, increase was observed at day $72(\mathrm{p}=0.010)$. A. suum eggs in $\mathrm{BALB} / \mathrm{c}$ mice
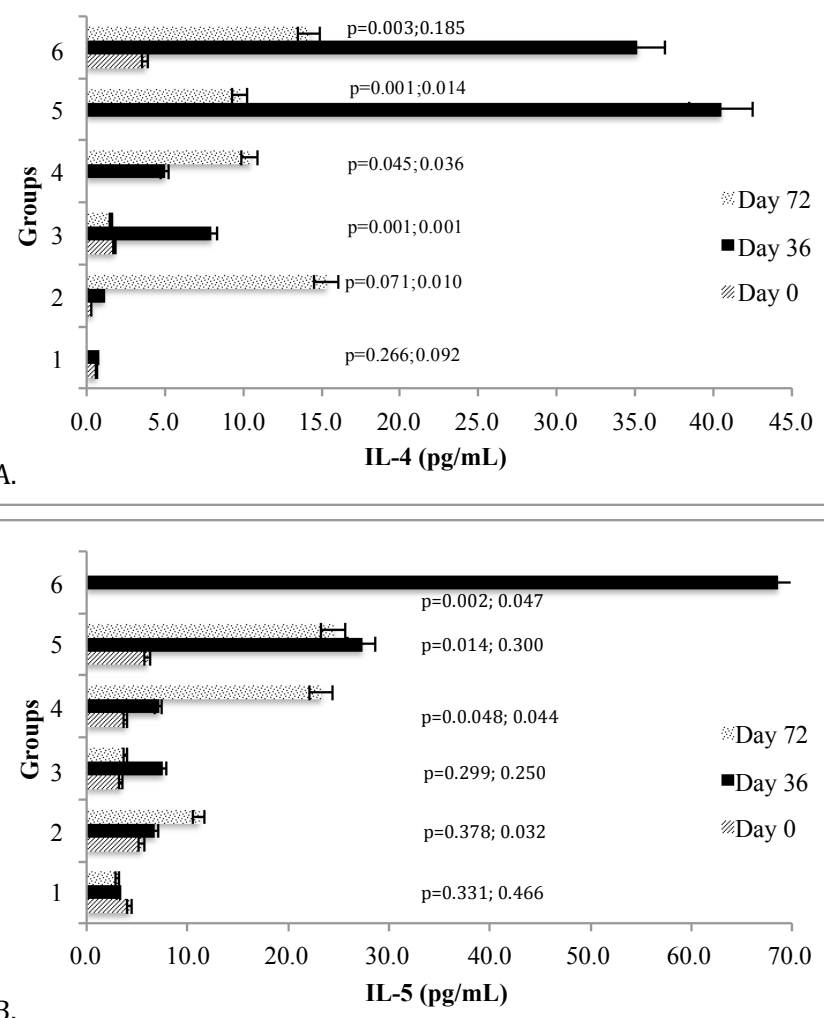

Figure 2: $A$. suum eggs and $D$. pteronyssinus extract upregulate production of IL-4 and IL-5. BALB/c mice were exposed to either $A$. suum eggs or $D$. pteronyssinus extract or both. Levels of IL- 4 and IL-5 were measured at day 0,36 and 72. P-values were determined using Repeated Measures Analysis of Variance (RMANOVA): $p=x ; y$ where $x=$ day 0 vs day 36 and $y=$ day 36 vs day 72. Results were presented as mean of the three trials because Mixed Model Analysis of Variance indicates that the results per trial do not significantly differ $(p=0.132)$. A. IL-4 levels. B, IL-5 levels. 
Citation: Pineda MRB, Ramos JDA (2012) Comparative Immunomodulatory Activity of Ascaris Suum Eggs and Dermatophagoides pteronyssinus Extract in BALB/C Mice: Cytokine and Immunoglobulin Regulations. J Aller Ther 3:119. doi:10.4172/2155-6121.1000119

upregulate the production of IL-4. While in group 3, marked increased in IL-4 production was observed immediately in mice exposed to $D$. pteronyssinus extract from day 0 to day $36(\mathrm{p}=0.001)$ and decreased significantly at day $72(\mathrm{p}=0.001)$. IL-4 levels also increased in group 4 after infection with $A$. suum from day 1 to $36(\mathrm{p}=0.045)$ and after exposure to $D$. pteronyssinus extract from day 37 to $72(\mathrm{p}=0.036)$. In groups 5 and 6, IL-4 level increased at day $36(\mathrm{p}=0.001 ; \mathrm{p}=0.003)$ and decreased at day $72(\mathrm{p}=0.014 ; \mathrm{p}=0.185)$ but still significantly higher than that of day $0(\mathrm{p}=0.028 ; \mathrm{p}=0.077)$.

Similarly, in group 2 , IL-5 increased slightly at day $36(\mathrm{p}=0.378)$ and upregulated at day $72(\mathrm{p}=0.032)$. IL-5 level in group 3 increased after administration of $D$. pteronyssinus extract, although not statistically significant $(\mathrm{p}=0.299)$ and decreased at day $72(\mathrm{p}=0.250)$. IL-5 also increased in group 4 after infection with A. suum at day $36(\mathrm{p}=0.048)$ and after exposure to $D$. pteronyssinus ( $\mathrm{p}=0.044$ ). Comparing the levels of IL-5 in group 3 at day 36 and group 4 at day 72, IL-5 in group 4 was markedly elevated ( $\mathrm{p}=0.044)$. In group $5, \mathrm{IL}-5$ increased markedly at day $36(\mathrm{p}=0.014)$ and decreased slightly at day 72 after administration of A. suum eggs ( $\mathrm{p}=0.300$ ). In group 6 , IL-5 level increased significantly at day $36(\mathrm{p}=0.002)$ and decreased at day $72(\mathrm{p}=0.047)$. Group 1 maintained a constant level of IL-5 throughout the experiment from day 0 to 36 and to 72 ( $\mathrm{p}=0.331 ; 0.466)$ (Figure 2B).

\section{A. suum upregulates and modulates IL-10 Production in $D$. pteronyssinus-induced allergy}

Upregulation of IL-10 production was observed in BALB/c mice infected with $A$. suum eggs. Group $1(\mathrm{p}=0.182 ; 0.355)$ and group $3(\mathrm{p}=0.247 ; 0.0172)$ did not show significant increase in the level of IL-10 (Figure 3). In group 2, administration of A. suum eggs induced significant IL-10 production at day $36(\mathrm{p}=0.036)$ and increased further at day $72(\mathrm{p}=0.255)$. Significant IL-10 production was also observed in group $4(\mathrm{p}=0.050)$ at day 72 . A. suum eggs induced a slight increase in IL-10 at day 36 and markedly increased at day 72 after administration of $D$. pteronyssinus extract. D. pteronyssinus extract alone did not induce significant IL-10 production as seen in group 3. A. suum eggs upregulated the levels of IL-10. Administration of D. pteronyssinus extract prior to and simultaneously with administration of $A$. suum eggs did not induce IL-10 production as seen in groups 5 and 6 ( $p>0.05)$.

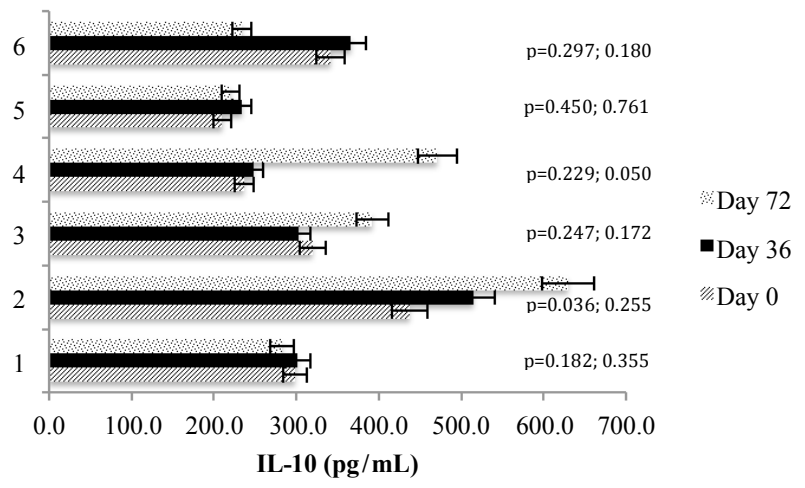

Figure 3: $A$. suum eggs upregulates the level of $\mathrm{IL}-10$ in $B A L B / c$ mice. $B A L B / c$ mice were exposed to either $A$. suum eggs or $D$. pteronyssinus extract or both Level of IL-10 was measured at day 0,36 and 72 . P-values were determined using RMANOVA: $p=x ; y$ where $x=$ day 0 vs day 36 and $y=$ day 36 vs day 72 . Results were presented as mean of the three trials because Mixed Model Analysis of Variance indicates that the results per trial do not significantly differ $(p=0.854)$

\section{D. pteronyssinus extract caused allergic symptoms on $\mathrm{BALB} / \mathrm{c}$ mice}

Mice in groups 3 and 5 developed allergic symptoms. Allergic
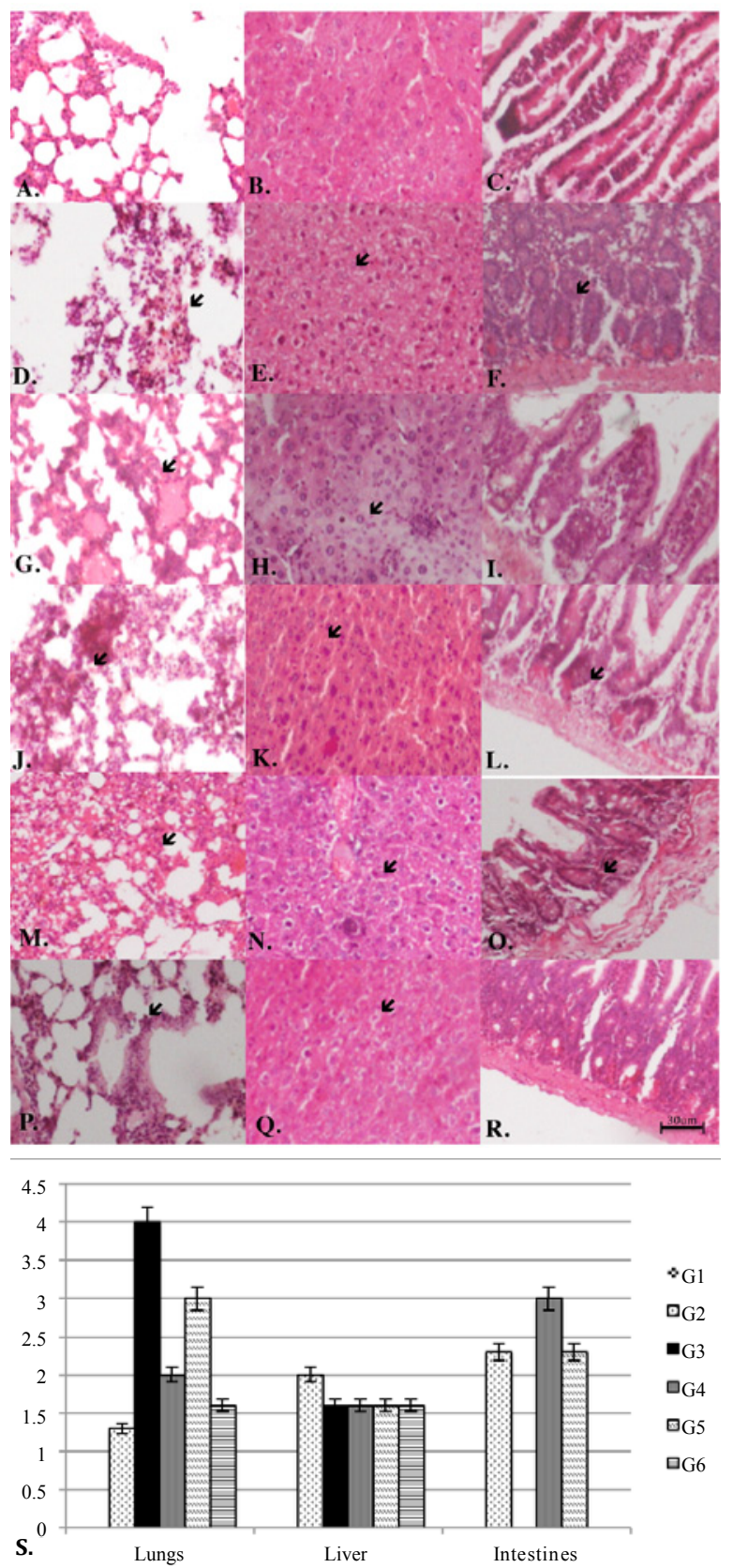

Figure 4: $A$. suum eggs and $D$. pteronyssinus extract affected the lungs, liver and intestines of BALB/c mice (400x magnification). A-C: Lungs, liver and small intestines of group 1 mice. D-R: Lungs, liver and intestines of group 2 (D-F), 3 (G-I), 4 (J-L), 5 (M-O), 6 (P-R). S: Levels of eosinophilia, edema and cell damage in the lungs; gross pathology, cellular infiltrate and necrosis in the liver; and morphological damage in the intestines were scored. Scores are presented as mean $\pm S D, n=3$. Pictures shown are from single mice per group and are representative of all mice examined in a group. Arrows indicate important pathological changes in the tissues such as congestion with neutrophilic infiltrates $(D, J, M, P)$, focal hyperplastic changes $(F)$, mild inflammation $(G)$, atypia with lymphocytic infiltrates $(H)$, atypia with lymphocytic infiltrates $(K)$, atrophic villi $(\mathrm{L})$, hyperplastic changes $(\mathrm{N})$, hypertrophied villi $(\mathrm{O})$, and focal microsteatosis $(Q)$ 
Citation: Pineda MRB, Ramos JDA (2012) Comparative Immunomodulatory Activity of Ascaris Suum Eggs and Dermatophagoides pteronyssinus Extract in BALB/C Mice: Cytokine and Immunoglobulin Regulations. J Aller Ther 3:119. doi:10.4172/2155-6121.1000119

symptoms were observed after administering $D$. pteronyssinus extracts for 10 consecutive days and lasted until the end of the experiment. 8 out of 15 mice ( 3 in trial 1, 3 in trial 2, and 2 in trial 3 ) in group 3 and 7 out of 15 mice in group 5 ( 2 in trial 1,3 in trial 2 and 2 in trial 3) experienced blepharitis (eyelid swelling and inflammation), nasal inflammation, inflammation of the neck and either the upper or lower limbs. These symptoms were not observed in groups 1,2, 4, and 6.

Microscopic analysis showed that lung, liver, and intestinal tissues from groups 2, 3, 4, 5, and 6 differed histologically from those of uninfected BALB/c mice (group 1). Lungs, liver and small intestines of group 1 showed no pathological abnormality (Figures 4A-4C). Group 2 (Figure 4D) and group 6 (Figure 4P) mice showed moderate interstitial edema and congestion accompanied by moderate to dense interstitial neutrophilic infiltrates with sprinkling of lymphocytes. Peribronchial and moderate perivascular lymphocytic infiltrates are likewise appreciated. Group 3 mice (Figure 4G) showed mild inflammatory process. Group 4 mice (Figure 4J) showed moderate interstitial edema and congestion accompanied by moderate interstitial neutrophilic infiltrates. Group 5 mice (Figure $4 \mathrm{M}$ ) showed mild to moderate interstitial edema and congestion accompanied by moderate interstitial neutrophilic infiltrates.

Liver tissues of mice infected with A. suum eggs (Figure $4 \mathrm{E}$ ) showed mild perivascular lymphocytic infiltrates. Group 3 mice (Figure $4 \mathrm{H}$ ) showed reactive atypia with mild perivascular lymphocytic infiltrates. Mild lymphocytic infiltrates often forming clusters were seen. Group 4 mice (Figure $4 \mathrm{~K}$ ) showed mild atypia with lymphocytic infiltrates. Group 5 mice (Figure $4 \mathrm{~N}$ ) showed hyperplastic changes with pleomorphism and hyperchromasia of hepatocytes. Group 6 mice (Figure 4Q) showed focal microsteatosis.

Normal appearance of the small intestines was observed from the tissues of mice in groups 1, 3, and 6 (Figures 4C,4I,4R). Group 2 mice (Figure 4F) showed focal hyperplastic changes. Group 4 mice (Figure $4 \mathrm{~L}$ ) showed atrophic villi. And group 5 mice (Figure 4O) showed hyperplastic changes and hypertrophied villi. All pathologic changes were scored following the criteria discussed above (Figure 4 S). Slides of each organ per group of mice exhibited similar pathologic changes, except for liver specimen of mice 2 of group 2, with normal histological appearance (not shown).

\section{D. pteronyssinus extract upregulates $D$. pteronyssinus-specific IgE and $A$. suum-specific IgE and IgG}

Anti-D. pteronyssinus IgE of group 3 mice increased significantly after administration of $D$. pteronyssinus extract and increased further at day $72(\mathrm{p}=0.010 ; \mathrm{p}=0.070)$ as seen on Figure 5A. In group 5 mice, administration of $A$. suum eggs lowered anti-D. pteronyssinus IgE level $(\mathrm{p}=0.159)$. Comparing this with group 3 mice, instead of continuously increasing the level of anti- $D$. pteronyssinus IgE up to day 72 , the level of anti-D. pteronyssinus IgE on allergic mice decreased upon administration of $A$. suum eggs. Anti-D. pteronyssinus IgE of group 2 mice after oral administration of $A$. suum eggs increased slightly but not significantly ( $\mathrm{p}=0.006)$. Instead of increasing the level of anti- $D$. pteronyssinus $\operatorname{IgE}$ as seen in group 3 group, administration of $D$. pteronyssinus extract to parasitized mice (group 4) decreased the level of anti-D. pteronyssinus IgE ( $\mathrm{p}=0.001)$. In group 6 mice, where both A. suum eggs and $D$. pteronyssinus extract were given simultaneously, anti-D. pteronyssinus IgE absorbance level did not change significantly from day 0 to day 36 and day 36 to day $72(\mathrm{p}=0.378 ; \mathrm{p}=0.490)$.

Anti-A. suum IgE level of group 2 did not significantly change after administration of $A$. suum eggs ( $\mathrm{p}=0.780 ; \mathrm{p}=0.647$ ) (Figure 5B). On the other hand, group 3 showed an increased production of anti- $A$. suum IgE upon administration of $D$. pteronyssinus extract $(\mathrm{p}=0.098)$ and was further upregulated at day $72(\mathrm{p}=0.000)$. IgE specific for $A$. suum did not increase after infection with $A$. suum eggs but increased significantly upon administration of $D$. pteronyssinus extract. In group 4, level of anti- $A$. suum IgE decreased after administration of D. pteornyssinus extract but not significantly $(\mathrm{p}=0.522)$. As with group 5 , administration of $A$. suum eggs lowered the absorbance level of anti-A. suum $\operatorname{IgE}(\mathrm{p}=0.172)$. Comparing this with the response of mice in group 3 , in group 3 anti- $A$. suum IgE continuously increased up to

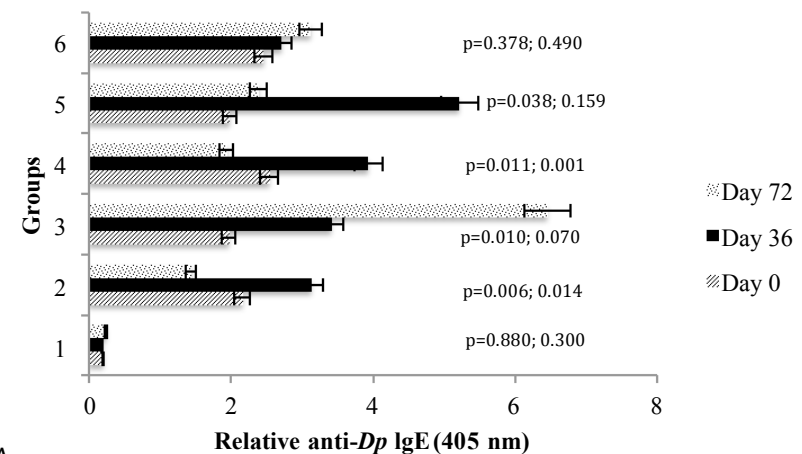

A.
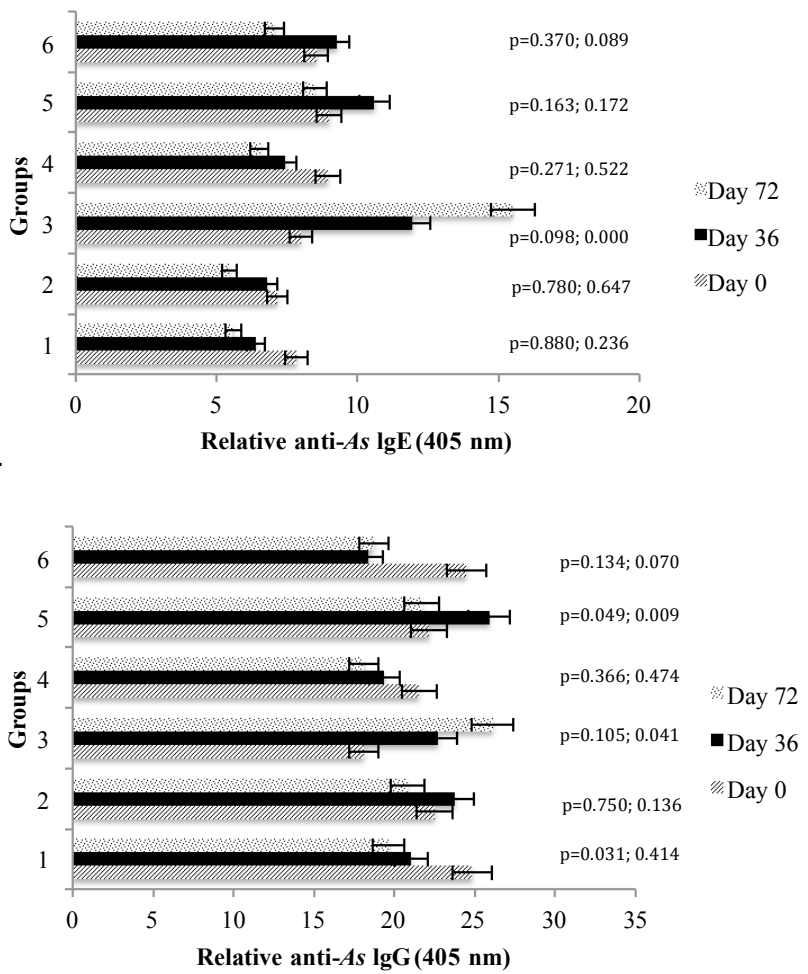

Figure 5: $D$. pteronyssinus extract enhances the production of $D$. pteronyssinus-specific $\lg$ E and $A$. suum-specific $\operatorname{lgE}$ and $\lg$. BALB/c mice were exposed to either $A$. suum eggs or $D$. pteronyssinus extract or both. Levels of antigen specific IgE and IgG were measured at day 0,36 and 72 . $P$-values were determined using RMANOVA: $p=x ; y$ where $x=$ day 0 vs day 36 and $y=$ day 36 vs day 72 . Results were presented as mean of the three trials because Mixed Model Analysis of Variance indicates that the results per trial do not significantly differ $(p>0.05)$. A: Relative anti- $D$. pteronyssinus IgE $B$ Relative anti-A. suum IgE C: Relative anti- $A$. suum lg. 
day 72 but in group 5 , the level of A. suum-specific antibody decreased upon administration of $A$. suum eggs on allergic mice. Instead of enhancing the production of anti- $A$. suum IgE, it has been observed that $A$. suum eggs decreased the level of A. suum-specific IgE. D. pteronyssinus extract, on the other hand, increased the level of anti- $A$. suum IgE. In group 6, level of anti-A. suum IgE did not significantly change $(\mathrm{p}=0.370 ; \mathrm{p}=0.089)$.

Anti-A. suum IgG level of group 2 mice increased slightly but not significantly after oral administration of $A$. suum eggs ( $\mathrm{p}=0.750$; $\mathrm{p}=0.136$ ) (Figure $5 \mathrm{C}$ ). Unlike in group 2, group 3 showed a significant increased in the production of anti- $A$. suum IgG upon administration of $D$. pteronyssinus extract ( $\mathrm{p}=0.105 ; \mathrm{p}=0.041)$. IgG specific for $A$. suum did not increase after infection with A. suum eggs but increased after administration of $D$. pteronyssinus extract. In group 4, level of anti- $A$. suum IgG did not significantly change after administration of $A$. suum eggs at day 36 and after administration of $D$. pteronyssinus extract at day $72(\mathrm{p}=0.366 ; 0.474)$. As with group 5 , administration of A. suum eggs lowered the level of anti-A. suum IgG ( $\mathrm{p}=0.009)$. In group 6, anti- $A$. suum IgG did not change significantly $(\mathrm{p}=0.134 ; \mathrm{p}=0.070)$.

Levels of anti- $D$. pteronyssinus IgE and anti-A. suum IgE and IgG of group 1 did not significantly change from day 0 to 36 to 72 ( $p>0.05$ ).

\section{Discussions}

In this study, immunomodulatory activity of $A$. suum and $D$. pteronyssinus in $\mathrm{BALB} / \mathrm{c}$ mice was investigated. Since both parasites and allergens are known Th2 cell inducers, three important Th2 cytokines were studied in this paper, namely, IL-4, IL-5, and IL10. Other interleukins such as IL-13 may also be involved in Th2 immune response but their involvement is not as vital as those examined. Although IL-13 is also important, studies have shown the overlapping role of IL- 4 and IL-13. IL- 4 and IL-13 are not identical but their biological activity is the same. They are structurally similar and reside within a cluster of cytokine genes $[25,26]$. Oral administration of A. suum eggs (group 2) induced significant IL-4, IL-5, and IL10 production in $\mathrm{BALB} / \mathrm{c}$ mice. While intranasal administration of D. pteronyssinus in $\mathrm{BALB} / \mathrm{c}$ mice (group 3) induced significant production of IL-4, and IL-5 and not of IL-10. In group 6, A. suum and D. pteronyssinus synergistically upregulated the levels of IL-4, and IL-5 but not of IL-10. Comparing the levels of these interleukins in groups 2, 3 , and 6, it can be observed that administration of both A. suum and D. pteronyssinus upregulated the levels of IL- 4 and IL-5 and only A. suum eggs enhanced the production of IL-10. IL-10 is a cytokine with antiinflammatory function, thus only A. suum infected BALB/c mice have the capacity to modulate inflammatory response through production of this interleukin.

Immunomodulatory activity of $D$. pteronyssinus in parasitized $\mathrm{BALB} / \mathrm{c}$ mice (group 4) and of A. suum in allergic BALB/c mice (group 5) were also monitored. Group 4 mice have increased levels of IL-4, IL5 , and IL-10 at day 72. While group 5 mice have decreased levels of IL-4, IL-5, and IL-10. IL-4 and IL-5 are interleukins with pro-inflammatory functions, while IL-10 has an anti-inflammatory function. Since activity of IL-10 counteracts the activity of IL- 4 and IL-5, IL-10 in group 4 was able to block inflammatory actions of IL- 4 and IL-5, and was exhibited by the absence of morphological inflammation in this group of mice as discussed above. Mice sensitized with $D$. pteronyssinus extract alone (group 3) and mice sensitized with D. pteronyssinus extract prior to administration of A. suum eggs (group 5) developed allergic inflammatory symptoms such as blepharitis, nasal inflammation, and/or neck and limb inflammation, while $A$. suum infected mice (group 1) and mice infected with A. suum eggs prior to sensitization with $D$. pteronyssinus extract (group 4 ) and simultaneously with $D$. pteronyssinus extract (group 6) did not develop such allergic symptoms. In this study, we hypothesize that IL-10 production protected the mice against the damaging inflammatory responses due to sensitization to D. pteronyssinus extract. Enhanced IL-10 production in mice exposed to previous infection was observed as well in the results of other studies [27-30]. In the study of Mangan et al. instead of Ascaris infection, female BALB/c mice were exposed to Schistosoma mansoni, and results showed an increase allergen specific IL-4 and IL-10 [29]. Elevated IL-10 level protects the mice against allergic pulmonary inflammation. The use of S. mansoni infection to reduce airway inflammation was likewise observed in C57/B16 mice strain showing the effectiveness of chronic parasitic infection in inhibiting allergic airway inflammation via IL-10 production [30]. S. japonicum egg infection was also studied in BALB/C mice and results corroborated with other studies that IL-10 production inhibits antigen-induced airway inflammation and development of asthma [30]. In humans, the role of S. haematobium in atopy among children was studied, and found out that the parasite induced IL-10 is capable of suppressing atopy [31]. Another study used Heligosomoides polygyrus, a gastrointestinal nematode, as the experimental parasite to induce helminth infection in female BALB/c mice. The study showed that $\mathrm{H}$. polygyrus infection is capable of suppressing allergen-induced airway eosinophilia, bronchial hyperactivity and in-vitro allergen recall Th2 responses in an IL-10 dependent manner [27]. Protection against allergic airway inflammation is also observed in C57BL/6 mice infected with infectious muscle larvae of Trichinella spiralis. Reduction of allergic airway inflammation in this study is attributed to the increase of IL-10 and TGF. IL-10 inhibits expression of many pro-inflammatory cytokines, chemokines, and chemokine receptors, and mediates allergen tolerance after exposure to high doses of allergen in several mouse models such as BALB/c mice and C57BL/c mice $[15,32,33]$.

Results of this study showed increased levels of IL-4 and IL-5 in BALB/c mice infected with A. suum and exposed to D. pteronyssinus. IL-4 and IL-5 productions are markers of immune response against chronic exposure to house dust mites and certain parasites $[15,34,35]$. In this present study, similar regulation of IL- 4 and IL-5 was observed in both allergic mice and parasitized mice. IL-4 regulates allergic conditions and is also the protective immune response against helminthes and other extracellular parasites. IL-5 also contributes to induction of airway hyperreactivity in cases of allergy and asthma [33]. In previous studies, to regulate immune response against allergies, IL-4 production is a good target. Lowering IL-4 production balances immune response in terms of lowering IgE and eosinophil productions, and increasing interferon- $\gamma$, interferon- $\alpha$ and Th1 response [36]. However, in this present study, no lowering of IL-4 was observed to balance allergic response. Instead, there was enhanced production of IL-10. A study on the determination of the importance of IL-4 in airway inflammation was done to determine if absence of IL- 4 would preclude immune response against chronic exposure to house dust mites (HDM). Results of this study showed that even in the absence of IL-4, allergic response against HDM is still possible through emergence of Th1 immunity. Thus, lowering IL-4 is not a potential candidate in preventing immune response against exposure to HDM. However, lack of IL- 4 in mice causes defects in Th2 cell differentiation and reduces IgE and IgG1 $[33,37]$. Studies targeting IL-5 has been a topic of several researches to regulate allergic response, but is not yet proven because of conflicting results. However, in patients with eosinophilic asthma, reducing IL-5 is highly correlated with reduced exacerbations and eosinophils in blood and sputum [38]. Results of the previous studies 
mentioned above indicate that downregulating the production of IL-4 and IL-5 does not protect the mice from allergic reactions. In group 4, A. suum infected mice might have protected the mice against D. pteronyssinus-induced allergy through production of IL-10 but not through downregulation of IL-4 and IL-5. While in group 5, A. suum infection in allergic BALB/c mice downregulated the levels of IL-4, and IL-5. Simultaneous infection with A. suum and allergic induction with D. pteronyssinus did not cause synergistic immune response in BALB/c mice but rather counteracts each other.

In terms of antibody productions, no significant increase in the relative level of IgE specific to A. suum was detected in A. suum infected mice (group 2). IgE, according to studies, is related to immunity rather than to exposure to infection and are usually produced only in cases of acute infection $[39,40]$. In acute infection, IgE is produced to combat the invading parasite together with eosinophils. Eosinophil degranulates against the parasite because parasites are too big to be phagocytized. Thus, IgE and eosinophil act as the host's protective mechanism against parasites $[41,42]$. Production of parasite-specific IgE is indicative of the host immunity against the parasite and is associated with resistance to infection or re-infection $[12,41]$. In this study, mice were infected with A. suum eggs to mimic chronic infection in humans following the protocol of Schopf et al. [14] with slight modification. The chronic parasitism was achieved and is indicated by the non-upregulation of As-specific IgE. As discussed in previous paragraphs, production of IL4, IL-5, and IL-10 are enhanced in infected mice as compared to normal mice. Production of these interleukins may also have exerted an effect on the production of antibodies. IL- 4 is a known cytokine that enhances antibody switching to IgE while IL-10 enhances antibody switching to IgG [43]. Since both IL-4 and IL-10 where markedly elevated in infected mice, effect of each cytokine counteracts each other, thus antibody switching is modulated. Presence of IL-10 can differentially regulate B-cells stimulated by IL-4 to produce IgG instead of IgE [44]. One study discussed three possible specific immune response against parasites: (1) host can be resistant to infection by balancing Th1 and Th2 cells controlled by $\mathrm{T}$ regulatory cells where both IgE and IgG4 are present but more IgE is produced; (2) host can have uncontrolled inflammatory Th1 disease where severe inflammation is observed and there is low IgG4 and significantly high IgE; and (3) host can be susceptible to infection and chronic infection is developed leading to a 'modified Th2 cell response' where more IgG and IL-10 are produced and less IgE [45]. The third type of immune response is exhibited in this study, that is, IL-10 is produced significantly, IgG is increasing and IgE production is not upregulated. Modified Th2 response is dominated by the production of IL-10. Although IL-4 with a known function in IgE and IgG switching, is also produced in this study, the dominating IL10 inhibits B-cell switching to IgE while inducing production of IgG. Interestingly, a study conducted in an A. lumbricoides hyperendemic area, central province of Cameroon, measurable levels of IgG4 were detected in individuals infected and only $30 \%$ of them have detectable IgE levels. Individuals with detectable levels of IgE but not IgG4 had the lowest average levels of infection. Thus, IgG4 is positively correlated to the level of infection [12].

As seen on the results above, $D$. pteronyssinus extract was able to upregulate the production of A. suum-specific IgE and IgG. Based on previous studies, this upregulation can be accounted to cross-reacting antigens present in both A. suum and D. pteronyssinus. Ascaris and mites like Dermatophagoides spp. are closely related invertebrates belonging to the Infra-kingdom Ecdysozoa, thus it is expected that they share similar allergens [40]. According to one study using Western blot analysis, antigens like tropomyosin and paramyosin from $A$. lumbricoides at approximately $35-37 \mathrm{kD}$ level and at $100 \mathrm{kD}$ level, respectively, match with the tropomyosin at approximately $37 \mathrm{kD}$ of HDM group 10 and with the paramyosins at $98-102 \mathrm{kD}$ level of HDM group 11 [46]. Further, another study identified high IgE reactivity with Blomia tropicalis and D. pteronyssinus at $40 \mathrm{kD}$ allergen in Ascaris. This $40 \mathrm{kD}$ allergen is confirmed as A. lumbricoides tropomyosin by Tandem LC-MS/MS and subsequent database search [47]. Tropomyosin and paramyosin are examples of cross-reactive antigens present in both $D$. pteronyssinus and A. suum. Tropomyosin is said to be highly conserved and antibodies against it may cross react to allergens from disparate species, thus termed as pan allergen. Paramyosin, on the other hand, is not as highly conserved and as cross-reactive as tropomyosin $[48,49]$. Tropomyosin found among invertebrates like house dust mites causes allergic reactions and is identified to have homology with the tropomyosins found in parasitic helminthes such as A. suum, Anisakis, Onchocerca and T. spiralis [50]. Paramyosin is found also in numerous invertebrates and in other parasites such as Clonorchis, Schistosoma, Fasciola, Paragonimus, Onchocerca and Anisakis and has been associated with the cross reactions observed between $A$. lumbricoides and house dust mites $[46,51,52]$. Another cross-reacting allergen found between Ascaris and dust mites (D. pteronyssinus and B. tropicalis) is glutathione-s-transferase at $23 \mathrm{kD}$ level [41]. In this present study, $D$. pteronyssinus extract enhanced the production of $A$. suum-specific IgE and IgG. The capacity of D. pteronyssinus to upregulate A. suumspecific IgE and IgG is supported by a study conducted to evaluate cross reactivities between house dust mites, such as $B$. tropicalis, $D$. pteronyssinus and D. farinae, and A. lumbricoides, and the presence of high binding IgE antigens in A. lumbricoides against sera of allergic patients has been identified [46]. On the one hand, results of the present study showed that $A$. suum eggs did not induce significant production of $D$. pteronyssinus-specific IgE. This non-upregulation of $D$. pteronyssinus-specific IgE by A. suum eggs even in the presence of cross reacting antigens coincides with the result of Valmonte et al. [46] which states that subjects with ascariasis showed low reactivity against house dust mite allergens and that cross reactive antigens are present in higher amounts in Ascaris than among house dust mites. Also, in another study, ABA-1 (ASC S1), a body fluid allergen 1 specific to A. suum, has not been found to be cross-reactive with house dust mite allergens and that house dust mites were not found to have epitopes for ABA-1. ABA-1 is a nematode polyprotein allergen found at $15 \mathrm{kD}$ level [41,47]. Mite allergens can cross-react with Ascaris epitopes and not vice versa $[46,47]$. D. pteronyssinus extract was able to upregulate the level of A. suum-specific IgE and IgG while A. suum eggs were not able to enhance the production of $D$. pteronyssinus-specific IgE and IgG. Upregulation of A. suum-specific IgE and IgG by D. pteronyssinus extract and non-upregulation of $D$. pteronyssinus specific IgE and IgG by A. suum eggs indirectly indicates and supports the idea that parasitism may protect an individual against allergic disorders but not vice versa. This is supported by the study of Valmonte et al. where ascariasis subjects showed low reactivity against HDM allergens and this low reactivity suggests that parasite products may be used as reagents to alleviate allergic disease[46]. Furthermore, another study by Flohr et al. in 2006 conform to this result that geohelminth infection lowers the risk of allergic sensitization thus components derived from parasites may be used as therapeutic regimens against allergy [53].

Histopathologic analysis of liver, lungs and small intestines were done to determine the pathological effect of $D$. pteronyssinus and $A$. suum in mice. Histological changes observed in the isolated tissue specimens of mice are due to either A. suum or D. pteronyssinus antigens. D. pteronyssinus extract caused edema, neutrophilic 
Citation: Pineda MRB, Ramos JDA (2012) Comparative Immunomodulatory Activity of Ascaris Suum Eggs and Dermatophagoides pteronyssinus Extract in BALB/C Mice: Cytokine and Immunoglobulin Regulations. J Aller Ther 3:119. doi:10.4172/2155-6121.1000119

Page 8 of 9

infiltrates, congestion, and mild inflammatory process as observed in the lung tissues of mice in group 3. Group 3 mice manifested to have allergic symptoms and elevated levels of IL-4 and IL5 and not IL-10. The levels of IL-4 and IL-5 were significantly elevated in allergic mice and have caused the inflammatory reactions of these mice as observed histologically and morphologically. Allergic symptoms and inflammation were not observed in group 2 group (parasitized mice) and group 4 (parasitized/allergic mice) mice histologically and morphologically. This was possibly due to the level of IL-10. Neutrophilic infiltrates were observed in groups 2, 3, 4, 5, and 6. Neutrophilic infiltrates are said to be common immunological responses against antigens [54,55]. Lungs, liver and small intestines from mice of groups 2 and 4 showed pathological abnormalities and are due to the migratory pattern of $A$. suum. Upon ingestion of $A$. suum eggs, eggs in the intestines hatched and released the larvae, which penetrated the intestinal wall to reach the venules and lymphatics. These larvae passed through the liver and lungs. Lungs, liver and small intestines of A. suum infected groups (2, 4 and 5) showed pathological conditions indicating that the ingested infective ova with larva inside may have hatched in the small intestines, larva migrated to the liver and to the lungs. A. suum infection caused hyperplastic changes and/ or atrophic villi in the intestines of the mice. Cellular infiltration, for example, in the lungs of group 2 mice might have led to inflammation because of obstruction due to accumulation of the cells. Lymphocytic infiltration in group 2, as well, caused mild edema and congestion. In the liver tissues, lymphocytic infiltrates were also observed. Presence of these lymphocytes in the liver tissues is associated with persistent infection [54,55]. Histopathological changes in the different organs of the mice were results of the host's immunological responses against the antigens, either A. suum eggs or D. pteronyssinus extract. Both antigens were capable of eliciting the immune response of BALB/c mice [18].

\section{Conclusions}

A. suum infection lowers the risk of developing D. pteronyssinusinduced allergic reaction in $\mathrm{BALB} / \mathrm{c}$ mice. A. suum infected $\mathrm{BALB} / \mathrm{c}$ mice were protected from $D$. pteronyssinus-induced allergy. Mice infected with $A$. suum eggs and exposed to D. pteronyssinus extract did not show any allergy symptoms morphologically and histologically and has decreased levels of anti-D. pteronyssinus IgE. A. suum and D. pteronyssinus are capable of upregulating IL-4 and IL-5 while only A. suum upregulates IL-10. D. pteronyssinus extract enhanced the production of A. suum-specific IgE and IgG and is accounted to crossreacting antigens present in $A$. suum and D. pteronyssinus. The possible role of IL-10 in the protection confers by $A$. suum infection against $D$. pteronyssinus-induced allergy needs further investigations. The use of IL-10 knock out mice may be useful. If proven, it will be the basis for the development of therapeutic regimens against allergy, which is a potential application of Hygiene Hypothesis. For future researches, analysis of bronchoalveolar lavage (BAL) is recommended, as well as other parameters such as neutrophil count and $\mathrm{T}$ cell recruitment to the lungs.

\section{Acknowledgments}

This study was funded by the Department of Science and Technology, Science Education Institute (Philippines), Philippine Association of Medical Technologists, Inc., Commission on Higher Education (Philippines), and Fund for Assistance to Private Education

\section{References}

1. Vercelli D (2006) Mechanisms of the hygiene hypothesis-molecular and otherwise. Curr Opin Immunol 18: 733-737.

2. Rook GA (2007) The hygiene hypothesis and the increasing prevalence of chronic inflammatory disorders. Trans R Soc Trop Med Hyg 101: 1072-1074.

3. Wilson MS, Maizels RM (2003) Regulation of allergy and autoimmunity in helminth infection. Clin Rev Allergy Immunol 26: 35-50.

4. Acevedo N, Mercado D, Vergara C, Sanchez J, Kennedy M, et al. (2009) Association between total immunoglobulin $\mathrm{E}$ and antibody responses to naturally acquired Ascaris lumbricoides infection and polymorphisms of immune system-related LIG-4, TNFSF13B and IRS2 genes. Clin Exp Immunol 157: $282-290$.

5. Erb KJ (2007) Helminths, allergic disorders and IgE-mediated immune responses: where do we stand? Eur J Immunol 37: 1170-1173.

6. Elliott D, Summers R, Weinstock J (2007) Helminths as governors of immunemediated inflammation. Intl J Parasitol 37: 457-464.

7. Elston D (2006) The hygiene hypothesis and atopy: bring back the parasites? J Am Acad Dermatol 54: 172-179.

8. van Riet E, Hartgers FC, Yazdanbakhsh M (2007) Chronic helminth infections induce immunomodulation: consequences and mechanisms. Immunobiol 212 475-490.

9. Alcantara-Neves NM, Badaro SJ, dos Santos MC Pontes-de-Carvalho $\mathrm{L}$, Barreto ML (2010) The presence of serum anti-Ascaris lumbricoides IgE antiboides and of Trichuris trichiura infection are risk factors for wheezing and/ or atopy in preschool-aged Brazilian children. Respir Res 11: 114

10. Palmer LJ, Celedon JC, Weiss ST, Wang B, Fang Z, et al. (2002) Ascaris lumbricoides infection is associated with increased risk of childhood asthma and atopy in rural China. Am J Respir Crit Care Med 165: 1489-1493.

11. Goddey N, Osagie I, Maliki A (2010) Serum cytokines profiles in Nigerian children with Ascaris infection. Asian Pacific Journal of Tropical Medicine: 288 291.

12. Turner JD, Faulkner H, Kamgno J, Kennedy MW, Behnke J, et al. (2005) Allergen-specific IgE and IgG4 are markers of resistance and susceptibility in a human intestinal nematode infection. Microbes Infect 7: 990-996.

13. Enobe CS, Araujo CA, Perini A, Martins M, Macedo MS et al. (2006) Early stages of Ascaris suum induce airway inflammation and hyperreactivity in a mouse model. Parasite Immunol 28: 453-461.

14. Schopf L, Luccioli S, Bundoc V, Justice P, Chan CC, et al. (2005). Differential modulation of allergic eye disease by chronic and acute Ascaris infection. Invest Ophthalmol Vis Sci 46: 2772-2780.

15. Cates EC, Fattouh, R, Wattie J, Inman MD, Goncharova S, et al. (2004) Intranasal exposure of mice to house dust mite elicits allergic airway inflammation via GM-CSF-mediated mechanism. J Immunol 173: 6384-6392.

16. Fernandes JF, Taketomi EA, Mineo JR, Miranda DO, Alves R et al. (2010) Antibody and cytokine responses to house dust mite allergens and Toxoplasma gondii antigens in atopic and non-atopic Brazilian subjects. Clin Immunol 136 148-156.

17. Ramos JDA, Castillo MPS, del Rosario M, Gapay MAS, Go TP, et al. (2007) Allergenicity and cross-reactivity of 3 house dust mite among filipino allergic patients. Phil J Sci 136: 139-146.

18. Akinboye DO, Ovansa JU, Agbolade OM, Fawole O, Akinboye OO, et al (2009) Experimental culture of Ascaris species and histopathological effects on visceral organs or rats (Rattus) and mice (Microtus). J Life Phys Sci 3: 137-144.

19. Ramos J, Teo A, Ou K, Tsai L, Lee B, et al. (2003) Comparative allergenicity studies of native and recombinant Blomia tropicalis Paramyosin (Blo t 11). Allergy 58: 412-419.

20. Cheong N, Soon SC, Ramos JD, Kuo IC, Kolatkar PR, et al. (2003) Lack of human IgE cross-reactivity between mite allergens Blo t 1 and Der $p 1$. Allergy 58: $912-920$.

21. Hagel I, Cabrera M, Hurtado MA, Sanchez P, Puccio F, et al. (2007) Infection by Ascaris lumbricoides and bronchial hyper reactivity: an outstanding association in Venezuelan school children from endemic areas. Acta Trop 103: 231-241.

22. Elekes K, Helyes Z, Laszlo K, Sandor K, Pinter E, et al. (2008) Inhibitory effects of synthetic somatostatin receptor subtype 4 agonists on acute and chronic airway inflammation and hyperreactivity in the mouse. Eur J Pharmacol 578: 313-322.

23. Miller CM, Zakrzewski AM, Ikin RJ, Boulter NR, Katrib M, et al. (2011) Dysregulation of the inflammatory response to the parasite, Toxoplasma gondii, in P2X7 receptor-deficient mice. Int J Parasitol 41: 301-308. 
Citation: Pineda MRB, Ramos JDA (2012) Comparative Immunomodulatory Activity of Ascaris Suum Eggs and Dermatophagoides pteronyssinus Extract in BALB/C Mice: Cytokine and Immunoglobulin Regulations. J Aller Ther 3:119. doi:10.4172/2155-6121.1000119

24. Pope MR, Hoffman SM, Tomlinson S, Flemming SD (2010) Complement regulates TLR4-mediated inflammatory responses during intestinal ischemia reperfusion. Mol Immunol 48: 356-364.

25. Munitz A, Brandt EB, Mingler M, Finkelman FD, Rothenberg ME (2008) Distinct roles for IL-13 and IL-4 via IL-13 receptor alpha1 and the type II IL-4 receptor in asthma pathogenesis. Proc Natl Acad Sci U S A 105: 7240-7245.

26. Yao X, Zha W, Song W, He H, Huang M, et al. (2012) Coordinated regulation of IL-4 and IL-13 expression in human T cells: 3C analysis for DNA looping. Biochem Biophys Res Commun 417: 996-1001.

27. Kitagaki K, Businga TR, Racila D, Elliott DE, Weinstock JV, et al. (2006) Intestinal helminthes protect in a murine model of asthma. J Immunol 177 1628-1635.

28. Park HK, Cho MK, Choi SH, Kim YS, Yu HS (2010) Trichinella spiralis: infection reduces airway allergic inflammation in mice. Exp Parasitol 127: 539-544.

29. Mangan NE, van Rooijen N, McKenzie AN, Fallon PG (2005). Helminthmodified pulmonary immune response protects mice from allergen-induced airway hyperresponsiveness. J Immunol 176: 138-147.

30. Smits $H H$, Hammad $H$, van Nimwegen $M$, Soullie $T$, Willart MA, et al. (2007) Protective effect of Schitosoma mansoni infection on allergic airway inflammation depends on the intensity and chronicity of infection. J Allergy Clin Immunol 120: 932-940.

31. van den Biggelaar $A H$, van Ree $R$, Rodrigues LC, Lell $B$, Deelder AM, et al. (2000) Decreased atopy in children infected with Schistosoma haematobium: a role for parasite-induced interleukin-10. Lancet 356: 1723-1727.

32. Mege JL, Meghari S, Honstettre A, Capo C, Raoult D (2006). The two faces of interleukin 10 in human infectious diseases. Lancet Infect Dis 6: 557-569.

33. Akdis M, Burgler S, Crameri R, Eiwegger T, Fujita H, et al. (2011) Interleukins, from 1 to 37 , and interferon- $y$ : receptors, functions, and roles in diseases. $J$ Allergy Clin Immunol 127: e1-e70.

34. Dold C, Holland CV (2010) Ascaris and ascariasis. Microbes Infect: 13: 632 637

35. Johnson JR, Wiley RE, Fattouh R, Swirski FK, Gajewska BU, et al. (2004) Continuous exposure to house dust mite elicits chronic airway inflammation and structural remodeling. Am J Resp Critic Care Med 169: 378-385.

36. Xie QM, Wu X, Wu HM, Deng YM, Zhang SJ, et al. (2008) Oral administration of allergen extracts from Dermatophagoides farinae desensitizes specific allergen-induced inflammation and airway hyperresponsiveness in rats. Int Immnuopharmacol 8: 1639-1645.

37. Chen ZG, Li M, Chen YF, Ji JZ, Li YT, et al. (2009) Effects of dermatophagoides pteronyssinus allergen specific immunotherapy on the serum interleukin-13 and pulmonary functions in asthmatic children. Chin Med J 122: 1157-1161.

38. Gause WC, Urban JF Jr, Stadecker MJ (2003) The immune response to parasitic helminthes: insights from murine models. Trends Immunol 24: 269277.

39. MacDonald AS, Araujo MI, Pearce EJ (2002) Immunology of parasitic helminth infection. Infect Immun 70: 427-433

40. Weiss ST (2000) Parasites and asthma/allergy: What is the relationship? J Allergy Clin Immunol 105: 205-210.

41. Acevedo N, Caraballo L (2011) IgE cross-reactivity between Ascaris lumbricoides and mite allergens: possible influences on allergic sensitization and asthma. Parasite Immunol 33: 309-321.

42. Winter WE, Hardt NS, Fuhrman S (2000) Immunoglobulin E: Importance in parasitic infections and hypersensitivity responses. Arch Pathol Lab Med 124 1382-1385.

43. Chaplin DD (2010) Overview of the immune response. J Allergy Clin Immuno 125: S3-S23.

44. Liu AH, Szefler SJ (2003) Advances in childhood asthma: Hygiene hypothesis, natural history, and management. J Allergy Clin Immunol 111: S785-S792.

45. Maizels RM, Yazdanbakhsh M (2003) Immune regulation by helminth parasites: cellular and molecular mechanisms. Nat Rev Immunol 3: 733-744.

46. Valmonte GR, Cauyan GA, Ramos JD (2012) IgE cross reactivity between house dust mite allergens and Ascaris lumbricoides antigens. Asia Pacific Allergy 2: 35-44
47. Acevedo N, Sánchez J, Erler A, Mercado D, Briza P, et al. (2009) IgE reactivity between Ascaris and domestic mite allergens: the role of tropomyosin and the nematode polyprotein ABA-1. Allergy 64: 1635-1643.

48. Santos AB, Rocha GM, Oliver C, Ferriani VP, Lima RC, et al. (2008) Crossreactive $\mathrm{lgE}$ antibody responses to tropomyosins from Ascaris lumbricoides and cockroach. J Allergy Clin Immunol 121: 1040-1046.

49. Thomas WR, Smith WA, Hales BJ (2004) The Allergenic specificities of the house dust mite. Chang Gung Med J 27: 563-569.

50. Sereda MJ, Hartmann S, Lucius R (2008) Helminths and allergy: the example of tropomyosin. Trends Parasitol 24: 272-278.

51. Park TJ, Kang JM, Na BK, Sohn WM (2009) Molecular cloning and characterization of a paramyosin from Clonorchis sinensis. Korean J Parasito 47: 359-367.

52. Zhao QP, Moon SU, Na BK, Kim SH, Cho SH, et al. (2007) Paragonimus westermani: biochemical and immunological characterizations of paramyosin. Exp Parasitol 115: 9-18.

53. Flohr C, Tuyen LN, Lewis S, Quinnell R, Minh TT, et al. (2006) Poor sanitation and helminth infection protects against skin sensitization in Vietnamese children: A cross-sectional study. J Allergy Clin Immunol 118: 1305-1311.

54. Sicherer SH, Leung DY (2010) Advances in allergic skin disease, anaplylaxis, and hypersensitivity reactions to foods, drugs, and insects in 2009. J Allergy Clin Immunol 125: 85-97.

55. Thoolen B, Maronpot RR, Harada T, Nyska A, Rousseaux C, et al. (2012) Proliferative and Nonproliferative Lesions of the Rat and Mouse Hepatobiliary System. Toxicol Pathol 38: 5S-81S. 